\title{
Improving voltage profile of load bus of wind generation system using DSTATCOM
}

\author{
Manju Aggarwal ${ }^{*}$ \\ DCRUST, Murthal, Haryana, India
}

\section{Madhusudan Singh}

Delhi Technological University, Delhi, India

\section{S K Gupta}

DCRUST, Murthal, Haryana, India

\begin{abstract}
In a low voltage distribution system with integrated wind plant, voltage stability is impacted by the large variation of load and wind penetration. The compensators like SVC and DSTATCOM are currently being used to address such issue of voltage instability. This paper analyses the impact of wind penetration and variation of active and reactive power of the load on voltage profile of a wind generation system with and without DSTATCOM. It also analyses the performance of the system during fault by calculating various parameters of the system. It has been demonstrated that voltage stability margin increases using DSTATCOM at different wind penetration levels. This system has been simulated and analysed in MATLAB 2011b using a power system toolbox under steady state and transient conditions.
\end{abstract}

Keywords: distributed generation, distribution static compensator, Squirrel cage induction generator; wind generation

Corresponding author: manju14111@gmail.com

\section{Introduction}

Renewable energy sources like wind, solar, biomass etc. have been explored worldwide as an alternative source of energy to supplement the capabilities of conventional energy sources. With the increase in power demand, extensive research and implementation has been done in the area of distributed generation (Ackermann et al., 2001). Wind energy is one of the most promising sources of electrical power among the renewable energy sources that needs no fuel and produces no waste or greenhouse gases. This makes wind energy a very attractive alternative source of power. However, there are several considerations to be taken into account before utilizing it for any commercial use. Studies by de Mello and Barker, (2000); Hatziargyriou et al., (2000); Georgilakis et al., (2008); and Coste et al. (2011) showed that wind generation integration may impose challenges like voltage fluctuation, poor power quality, voltage instability etc. Out of all these issues, the voltage instability needs special attention as it can potentially lead to complete voltage collapse in the system. There are several reasons for voltage instability like change in load, wind speed variations, faults at feeder line, wind energy penetration etc.

Most of the papers have analysed the voltage stability aspect in the distribution system with distributed generation using static load models and static compensators. Smith et al. (2001) explains that voltage regulation is the main issue in the rural distribution feeder which exacerbate due to distributed generation at the end of the feeder line.

Shen et al. (2012) analyses the impact of voltage fluctuation of distributed generation due to wind 
speed variation. The solution to these issues has been explained by Roy et al., (2011) using the cost effective combination of shunt capacitor and Distribution Static Compensator (DSTATCOM) for enhancing the voltage stability. The voltage stability margin of the system is improved with DSTATCOM using a voltage and power factor control strategy by Freitas et al. (2002). Lahacani et al. (2010) demonstrates the effect of wind speed variation on the voltage stability of the system and improvement with the application of DSTATCOM.

Allagui et al. (2014) showed that STATCOM contributes to controlling the grid voltage at PCC during fault conditions. Alonso et al. (2006); Ettehadi et al. (2012) and Abri et al. (2013) explained the use of optimization techniques to improve the stability margin by sizing and location of Distributed Generation (DG). The effect on voltage stability due to variation in load is explained by Roy et al. (2013) and Zamora et al. (2014) by using PV and QV curves. PV and QV curves represent the variation of voltage with active power and reactive power of the load respectively. PV curves are drawn for a fixed power factor and QV curves are the plot of voltage vs. reactive power for constant active power. Since the load is unpredictable, the active and reactive power of the load keeps changing. In this paper, the voltage profile for different values of active and reactive power has been observed by plotting the surface curves. The system behaviour is studied at different rated wind power with and without the use of DSTATCOM. The transient analysis is done by considering three phase fault at a bus and performance of the system is described by calculating settling time, rise time, integral square error etc.

This paper has been structured in five sections with the first section providing an introduction to the subject matter and the background of work already done in this area. Section 2 explains the voltage stability of a power system with section 3 highlighting typical challenges causing the voltage instability. Section 4 gives some of the popular solutions to the instability problem. A typical system and the solution using DSTATCOM control scheme has been elaborated in section 5 and 6 respectively. Section 7 covers the steady state and transient analysis of the system with and without DSTAT$\mathrm{COM}$ at different rated wind power. The results show that DSTATCOM is a powerful controller to improve the voltage stability margin as concluded in Section 8.

\section{Voltage stability and challenges of instability$$
\text { 2.1 Voltage stability }
$$

The voltage stability can be categorized as short term and long term with large signal and small signal effects. Large signal (disturbance) voltage stability is concerned with the system's ability to control voltages following large disturbances such as faults, loss of generation etc., whereas small disturbance voltage stability is concerned with system's ability to control voltages due to small perturbations such as incremental changes in system load (Kundur, 1999). For wind power applications, small disturbance for long term is considered.

\subsection{Challenges of voltage instability}

\subsubsection{Increase in loading}

The driving force for voltage instability is usually the loads and load characteristics. Hence, voltage stability, at times, is also called the load stability. With increase in load on a radial distribution network receiving end voltage decreases due to voltage drop in the line impedances when active and reactive powers flow through it. This in turn increases the stress on the high voltage network by increasing the reactive power consumption and further reducing the voltage which has an adverse impact such as overheating of generators and motors etc. PV and QV curves are used to analyse steady state voltage stability of the system.

\subsubsection{Faults}

Faults are kind of disturbances on power system. Voltage stability of a system is endangered when a disturbance increases the reactive power demand beyond the sustainable capacity of the available reactive power resources. During faults on the system, the induction generator may consume a large amount of reactive power as generator speed deviates from synchronous speed which can lead to a voltage stability problem.

In this paper, the effect of a three phase fault has been considered.

\subsubsection{Reactive power demand}

Distributed generation can be directly connected to the grid using am induction generator or indirectly interfacing using a power electronics converter. DG units that are equipped with a directly connected induction generators can affect the voltage stability margin negatively due to reactive power consumption (Allagui et al., 2014)

\subsubsection{Wind speed variation}

The wind speed variation may cause a voltage fluctuation, which may lead to voltage flicker at the point of common coupling. The wind speed is considered constant is this work

\subsubsection{Wind penetration level}

If wind constitutes a sizeable part of total generation then stability becomes a major issue. That size is defined by a Short Circuit Ratio (SCR) which is the ratio of rating of the system to wind generator power rating. An instability problem occurs when this ratio is less than 10 (Kothari, 2012). 


\section{Solutions to voltage stability problem 3.1 By proper location and sizing of distributed generation}

The voltage stability can be enhanced by optimal location and sizing of distributed generation, which is achieved by using optimization techniques.

\subsection{Compensation devices}

The capacitors provide the fixed compensation and they cannot enhance the stability performance of the system. Various FACTS devices are available like Static Var Compensator (SVC), Dynamic Voltage Regulator (DVR), and DSTATCOM etc. However, DSTATCOM has an edge over SVC in terms of its superior operational characteristics characteristics, lesser cost, smaller size etc., and moreover, it is not affected by the voltage variation at PCC.

In this work, voltage profile and stability have been improved with application of DSTATCOM.

\subsection{DSTATCOM}

The distribution static compensator is a shunt connected reactive power compensation device that is capable of generating or absorbing reactive power and to provide voltage support to a bus. In a renewable energy system, this is also used to improve the stability of the system. The reactive power imbalances can be minimized by using this compensation device. DSTATCOM is also capable of enhancing a fault ride through capability of the system.

\section{System description}

The proposed system consists of a grid, transformer, feeder line along with a wind generator and DSTATCOM as shown in Figure 1.

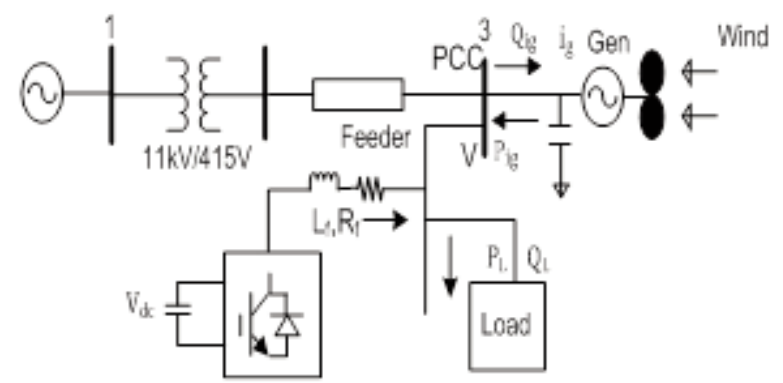

Figure 1: Basic structure of test system

The wind generation system is connected at the end of the feeder line at bus no. 3 and DSTATCOM at the same bus through filter inductor $\left(\mathrm{L}_{\mathrm{f}}\right)$ and a small resistance $\left(\mathrm{R}_{\mathrm{f}}\right)$. The wind generation system comprising squirrel cage induction generators (SCIG) driven by a fixed speed wind turbine. A DSTATCOM supplies the lagging or leading current to manage the constant terminal voltage at PCC during fault conditions. The detailed modelling of the turbine is given (Aggarwal, 2013). The equation describing the turbine is as follows:

$$
\begin{aligned}
& P_{m}=\frac{1}{2} C_{P}(\lambda, \beta) \rho \frac{\pi R^{2}}{2} v_{w}^{3} \\
& C_{P}(\lambda, \beta)= \\
& C_{1}\left({ }^{C_{2}} / \lambda_{i}-C_{3} \beta-C_{4}\right) \exp \left(-C_{5} / \lambda_{i}\right)+C_{6} \lambda
\end{aligned}
$$

\section{DSTATCOM control scheme}

The control scheme of DSTATCOM is shown in Figure 2. The reactive power support is provided by controlling a reactive current component. The reactive component of current $\left(\mathrm{i}_{\mathrm{q}}\right)$ is calculated by comparing the voltage at the point of common coupling with the reference voltage i.e. maximum value of desired A.C voltage $\left(V_{\text {ref }}\right)$. The active component of currents $\left(\mathrm{i}_{\text {pabc }}{ }^{*}\right)$ are derived by first calculating a unit vector template from a phase locked loop (PLL) by generating angle $\theta$ as:

$$
\begin{aligned}
& \mathrm{u}_{\mathrm{a}}=\sin (\theta) \\
& \mathrm{u}_{\mathrm{b}}=\sin \left(\theta-\frac{2 \pi}{3}\right) \\
& \mathrm{u}_{\mathrm{c}}=\sin \left(\theta+\frac{2 \pi}{3}\right)
\end{aligned}
$$

The active component of reference currents are derived using in phase unit vector template using eq. (6):

$$
\left[\begin{array}{l}
i_{p a} \\
i_{p b} \\
i_{p c}
\end{array}\right]=i_{p}\left[\begin{array}{l}
u_{a} \\
u_{b} \\
u_{c}
\end{array}\right]
$$

Where $\mathrm{i}_{\mathrm{p}}$ is the output of PI controller regulating $\mathrm{dc}$ bus voltage of DSTATCOM and also converter losses. Reactive components of a reference current are obtained as follows:

$$
\left[\begin{array}{l}
w_{a} \\
w_{b} \\
w_{c}
\end{array}\right]=\frac{\sqrt{3}}{2}\left[\begin{array}{ccc}
0 & -2 / 3 & 2 / 3 \\
1 & 1 / 3 & -1 / 3 \\
-1 & 1 / 3 & -1 / 3
\end{array}\right]\left[\begin{array}{l}
u_{a} \\
u_{b} \\
u_{c}
\end{array}\right]
$$

A reactive component of reference source current $\left(\mathrm{i}_{\text {qabc }}\right)$ is calculated using eq. (8):

$$
\left[\begin{array}{c}
\mathrm{i}_{\mathrm{qa}} \\
\mathrm{i}_{\mathrm{qb}} \\
\mathrm{i}_{\mathrm{qc}}
\end{array}\right]=\mathrm{i}_{\mathrm{q}}\left[\begin{array}{c}
\mathrm{w}_{\mathrm{a}} \\
\mathrm{w}_{\mathrm{b}} \\
\mathrm{w}_{\mathrm{c}}
\end{array}\right]
$$

Where $\left(\mathrm{i}_{\mathrm{q}}\right)$ is obtained by comparing it with the reference voltage. A PI controller processes the voltage error. 


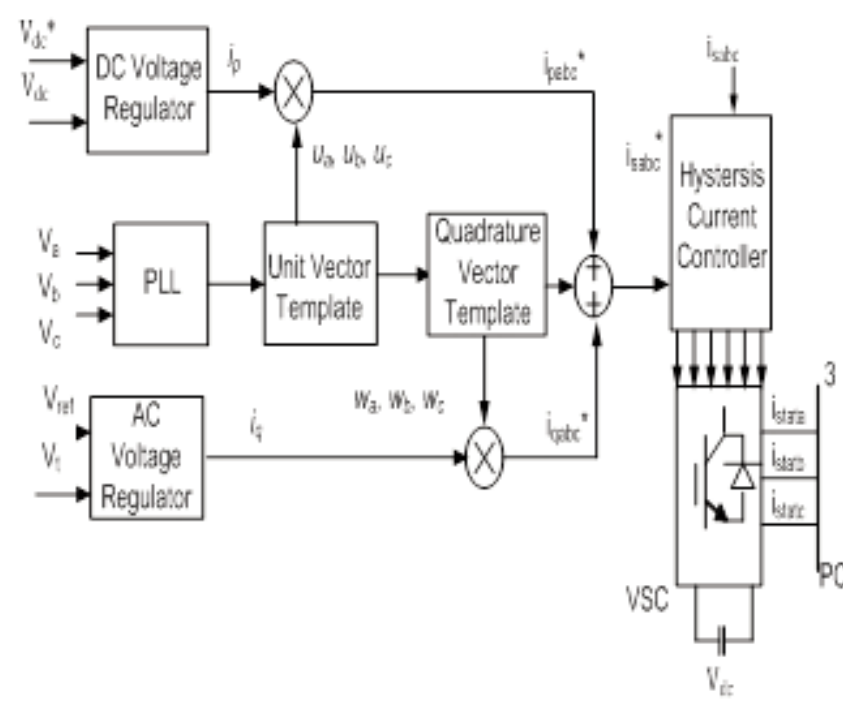

Figure 2: Control scheme of DSTATCOM

The amplitude of a reactive current to be produced by the STATCOM is decided by the output of the $\mathrm{PI}$ controller in the $\mathrm{AC}$ voltage control loop. In the inner current loop hysteresis the current controller is used, where source currents are compared with reference current derived from outer loop.

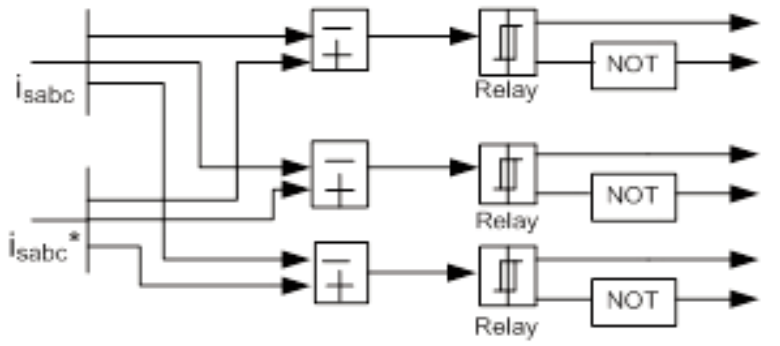

Figure 3: Hysteresis current controller

The hysteresis controller is used for tracking error. It adds a hysteresis band from $+\mathrm{h}$ to $-\mathrm{h}$ to the reference signal. The tracking error becomes better as the hysteresis band becomes narrower. As the band becomes narrower, the switching frequency becomes higher. This is obvious as the current touches and overshoots a narrower band more frequently resulting in the faster changing switch states. Unfortunately, high switching frequency results in increased losses culminating in increased heating in the power semiconductor devices. Thus the choice of a hysteresis band is a compromise between tracking error and inverter losses (Ghosh et al., 2002). The hysteresis band for this work is 0.1 , and this enables the source current controlling to be sinusoidal. This method is simple, robust and favourable as compared with other methods (Banerji et al., 2012)

\section{Simulation results}

\subsection{Impact of DSTATCOM}

Figures 4 and 6 represent the surface of the voltage profile for different values of active and reactive power without DSTATCOM. For each value of reactive load from -20kvar to 20kvar, the active load has been varied from zero to $80 \mathrm{~kW}$. Figures 5 and 7 represent the surface of the voltage profile of the same parameters with DSTATCOM. It is observed that the voltage profile is improved with application of DSTATCOM. The critical operating voltage is calculated at load bus for different wind penetration and it is demonstrated in Tables 1 and 2 that critical operating voltage limit has been increased with the use of DSTATCOM.

\subsection{Impact of wind penetration}

Figures 4 and 5 depict the surface plots of voltage for different values of active and reactive power with rated power of the wind generator. Figures 6 and 7 show the plots at $50 \%$ of rated power of the wind generator with decreased speed.

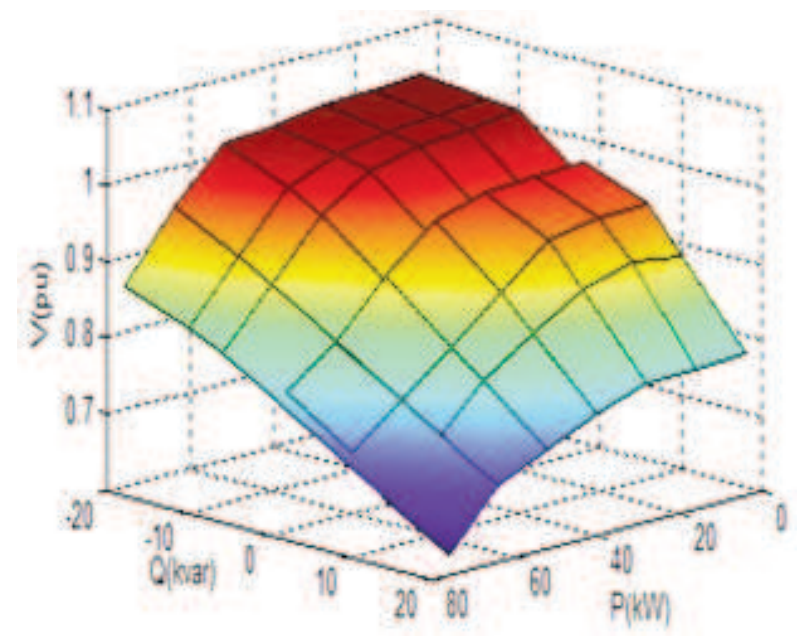

Figure 4: Variation in voltage (V) with active power $(P)$, reactive power $(Q)$ for rated wind power without DSTATCOM

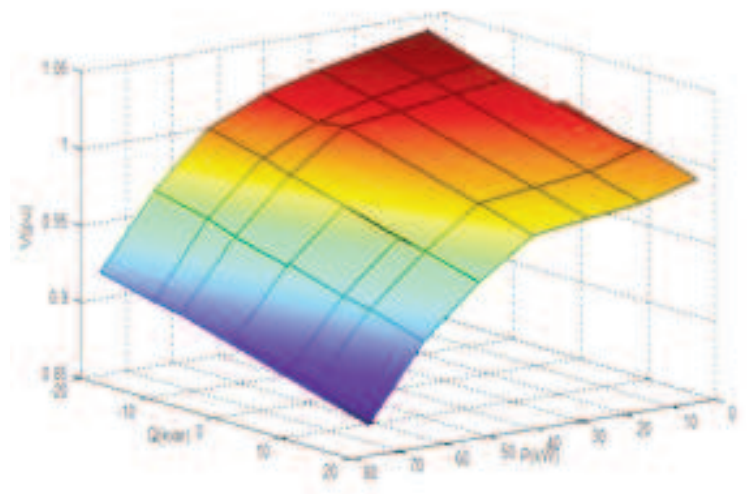

Figure 5: Variation in voltage (V) with active power $(P)$, reactive power $(Q)$ for rated wind power with DSTATCOM

It is observed that voltage profiles at load bus in Figures 4 and 5 are better than in Figures 6 and 7 as the wind generator is capable of supplying more active power at rated wind speed. 


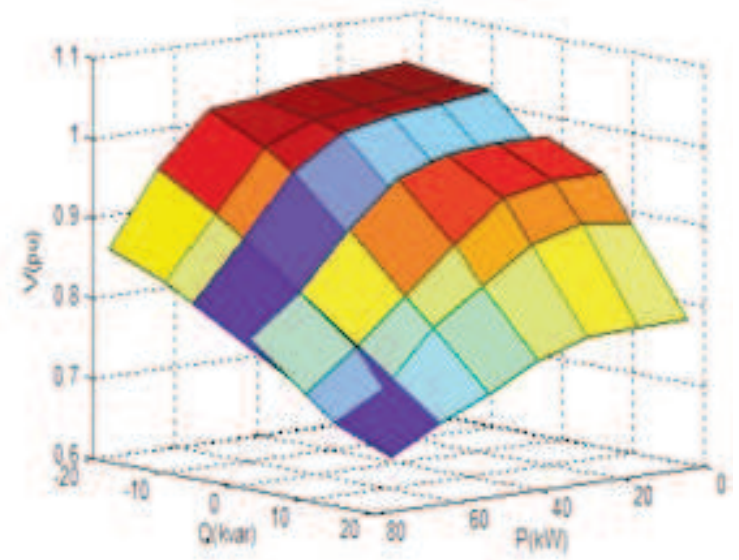

Figure 6: Variation in voltage (V) with active power $(P)$, reactive power $(Q)$ for rated wind power without DSTATCOM

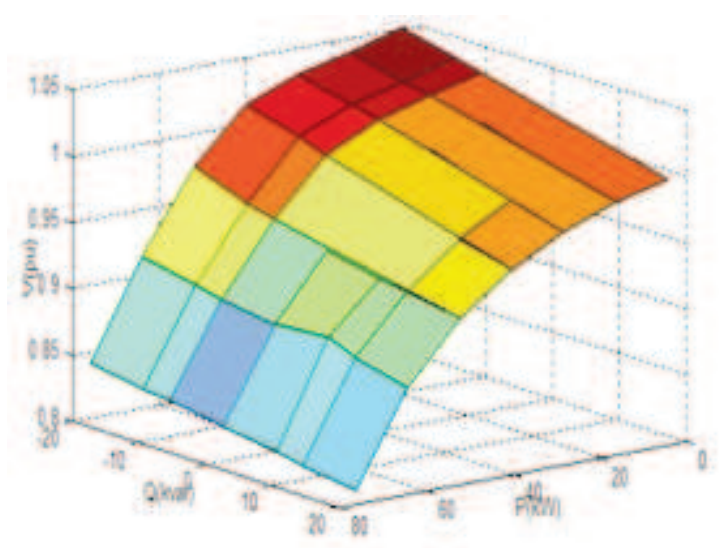

Figure 7: Variation in voltage (V) with active power $(P)$, reactive power $(Q)$ for $50 \%$ rated wind power with DSTATCOM

\subsection{Transient analysis: Impact of three phase fault}

For transient analysis, three phase fault is created near the grid at bus no. 1 for $150 \mathrm{~ms}$ for constant power load. The voltage goes down to zero volts during fault due to large reactive power consumption by tghe generator as shown in Figure 8 for rated wind generation. The decrease in voltage leads to decrease in torque and acceleration of the rotor. Figure 9 shows the change in voltage at PCC with $50 \%$ of the rated wind generation. It is demonstrated that DSTATCOM has improved the Settling time(Ts), Rise time(Tr), Integral absolute error (IAE), integral square error (ISE) and critical operating voltage of the system in both conditions as presented in Tables 1 and 2. The ISE is a measure of system performance by integrating the square of system error over a fixed interval of time. It is given by the equation (9):

$$
\text { ISE }=\int \Delta \mathrm{v}^{2} \mathrm{dt}
$$

Where $\Delta v$ is the change in voltage due to the three phase fault. IAE is the measure of absolute value of the system error over fixed interval of time. The equation (10) is given by:

$$
\mathrm{IAE}=\int|\mathrm{v}|^{2} \mathrm{dt}
$$

The values of Ts, Tr, IAE and ISE are more for rated wind generation which shows that higher wind penetration takes more time to settle, has higher error etc., which may lead to voltage instability of the system. Figure 10 shows the change in voltage for fault occurs on the PCC. For the threephase balanced fault at PCC, the DSTATCOM does not have the ability to let the wind turbine ride through this type of fault because voltage on its terminal will be zero. After the fault clearance DSTAT$\mathrm{COM}$ helps in reducing the time to clear the fault. Figure 11 shows the variation of generator speed during fault without and with DSTATCOM.

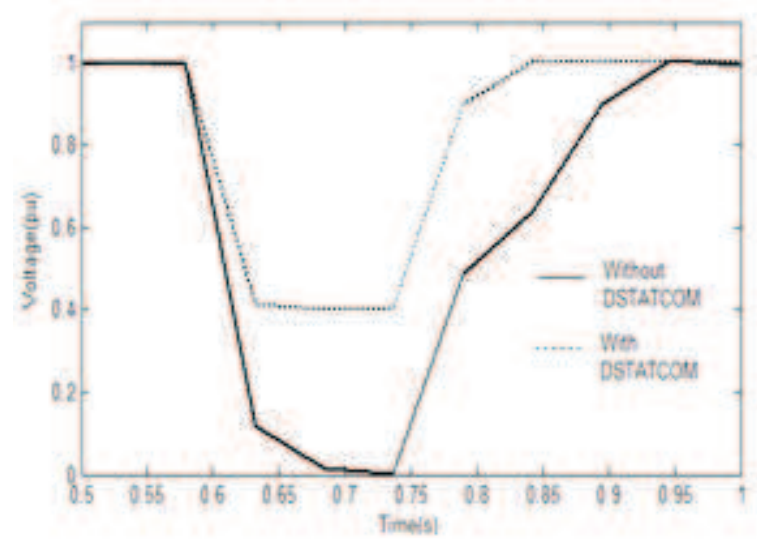

Figure 8: Voltage time curve for $100 \%$ wind generation

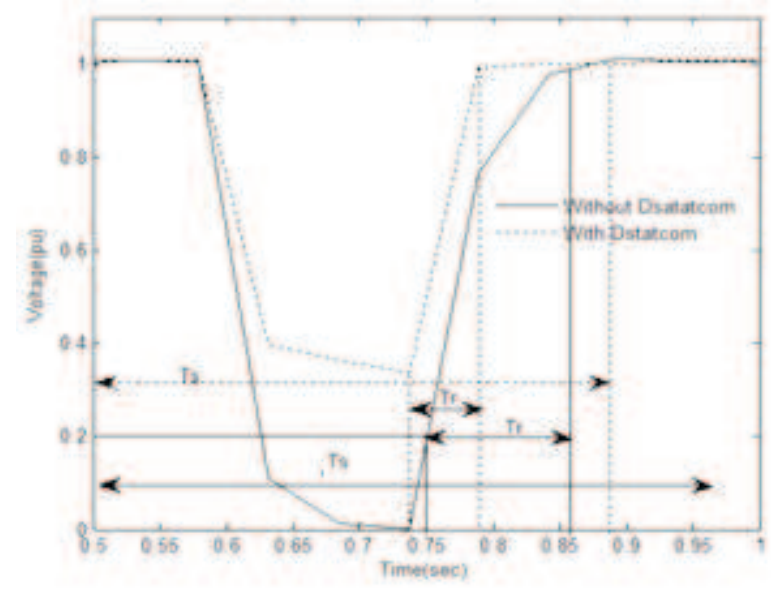

Figure 9: Voltage time curve for $\mathbf{5 0 \%}$ of rated wind power

\section{Conclusion}

This paper analyses the impact of wind penetration and the effect of active and reactive power on the voltage profile of load bus of system. The surface curves are plotted to observe the voltage profiles of the system at different values of active and reactive 
power. There is reduction in voltage at load bus by decreasing the rated wind power of the generator with decreased speed and with increase in active and reactive power of the load. It is observed that the application of DSTATCOM improves the voltage profile of the load bus and settling time, rise time, integral square error of the system during fault condition.

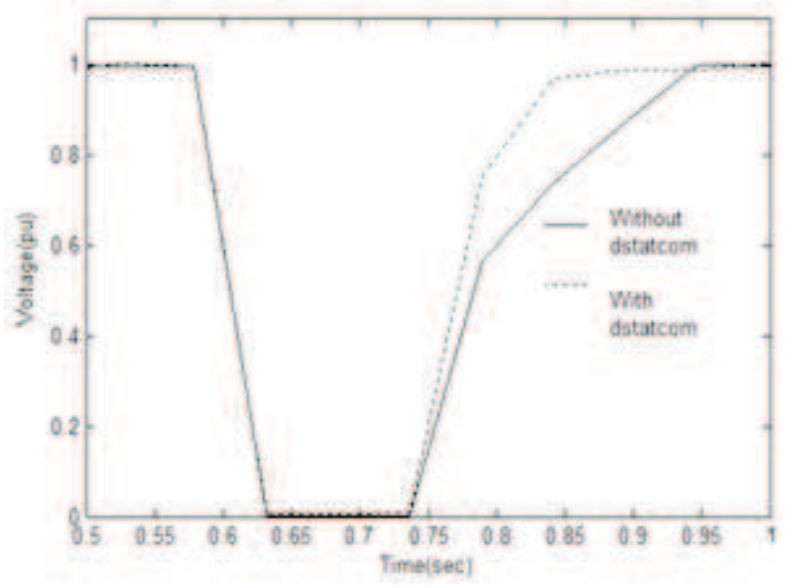

Figure 10: Voltage time curve for fault at PCC

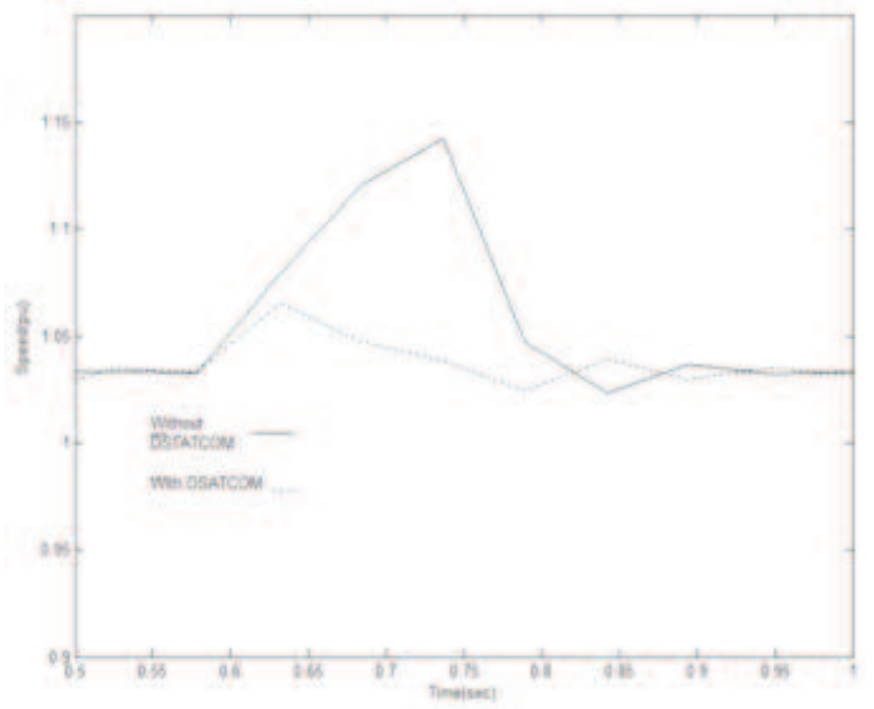

Figure 11: Speed time curve

Table 1: Performance of the system for $100 \%$ rated wind power with and without DSTATCOM

\begin{tabular}{lccccc}
\hline & $\begin{array}{c}T s \\
(s)\end{array}$ & $\begin{array}{c}\text { Tr } \\
(s)\end{array}$ & $\begin{array}{c}\text { ISE } \\
(p u)\end{array}$ & $\begin{array}{c}\text { IAE } \\
(p u)\end{array}$ & $\begin{array}{c}\text { Critical oper- } \\
\text { ating voltage } \\
(p u)\end{array}$ \\
\hline Without & & & & & \\
DSTATCOM & 1.007 & 0.212 & 0.155 & 0.19 & 0.655 \\
\hline With & & & & & \\
DSTATCOM & 0.976 & 0.024 & 0.08 & 0.14 & 0.85 \\
\hline
\end{tabular}

Table 2: Performance of the system for $\mathbf{5 0} \%$ rated wind power with and without DSTATCOM

Ts Tr ISE IAE Critical oper-

(s) (s) (pu) (pu) ating voltage (pu)

\begin{tabular}{llllll}
\hline Without & & & & & \\
DSTATCOM & 0.965 & 0.12 & 0.17 & 0.224 & 0.622 \\
\hline With & & & & & \\
DSTATCOM & 0.895 & 0.051 & 0.145 & 0.077 & 0.8 \\
\hline
\end{tabular}

\section{Appendix}

\begin{tabular}{|c|c|}
\hline \multicolumn{2}{|c|}{ DSTATCOM } \\
\hline Rated Power $\left(Q_{\text {stat }}\right)$ & $30 \mathrm{kvar}$ \\
\hline Rated Voltage $\left(\mathrm{V}_{\text {stat }}\right)$ & $415 \mathrm{~V}$ \\
\hline Line filter parameters $\left(\mathrm{L}_{\mathrm{f}}, \mathrm{R}_{\mathrm{f}}\right)$ & $5 \mathrm{mH}, 0.01 \mathrm{ohm}$ \\
\hline$\overline{\mathrm{DC}}$ bus voltage (Vdc) & $700 \mathrm{~V}$ \\
\hline$\overline{\mathrm{AC}}$ regulator(Kpq, Kiq) & $0.3,0.005$ \\
\hline \multicolumn{2}{|c|}{ Wind farm induction generator and Grid } \\
\hline $\begin{array}{l}\text { Grid power and rated voltage } \\
\left(\mathrm{P}_{\text {grid }}, \mathrm{V}_{\text {grid }}\right)\end{array}$ & $500 \mathrm{kVA}, 11 \mathrm{kV}$ \\
\hline $\begin{array}{l}\text { Feeder resistance }(\mathrm{R}) \text { and } \\
\text { inductance }(\mathrm{L}) / \mathrm{km}\end{array}$ & $0.247,3.317$ \\
\hline Rated Power $\left(\mathrm{P}_{\mathrm{ig}}\right)$ & $22 \mathrm{~kW}$ \\
\hline Rated Voltage $\left(\mathrm{V}_{\mathrm{pcc}}\right)$ & $415 \mathrm{~V}$ \\
\hline Stator resistance $\left(\mathrm{R}_{\mathrm{s}}\right)$ & $0.251 \mathrm{pu}$ \\
\hline Rotor resistance $\left(\mathrm{R}_{\mathrm{r}}\right)$ & $0.2481 \mathrm{pu}$ \\
\hline \multicolumn{2}{|c|}{ Stator and rotor reactance $\left(\mathrm{X}_{\mathrm{s}}, \mathrm{X}_{\mathrm{r}}\right) 0.52 \mathrm{pu}$} \\
\hline Inertial constant $(\mathrm{J})$ & $0.302 \mathrm{~kg} / \mathrm{m}^{2}$ \\
\hline Turbine rating & $22 \mathrm{~kW}$ \\
\hline Power coefficient of turbine $(\mathrm{Cp})$ & 0.48 \\
\hline Tip speed ratio $(\lambda)$ & 8.1 \\
\hline Blade angle $(\beta)$ & 0 \\
\hline Wind speed $\left(\mathrm{v}_{\mathrm{w}}\right)$ & $9 \mathrm{~m} / \mathrm{s}$ \\
\hline Turbine coefficients & $\begin{array}{l}c 1=0.5176 \\
c 2=116 \\
c 3=0.4 \\
c 4=5 \\
c 5=21 \\
c 6=0.006\end{array}$ \\
\hline
\end{tabular}

\section{References}

Abri, R.S.Al, Saadany, Ehab F., Atwa,Y.M. (2013). Optimal placement and sizing method to improve the voltage stability margin in a distribution system using distributed generation, IEEE Transaction on Power System, Vol. 28, No.1, pp.326-334.

Ackerman, T. Andersson, G. and Söde L. (2001). Distributed generation: a definition, Electric Power Systems Research Vol. 57, No.3, pp.195-204 Elsevier.

Aggarwal, M., Singh, M., and Gupta, S.K. (2012). Analysis and control of grid connected wind energy system with DSTATCOM, IEEE 5th Power India Conference (PICON'2012), pp.1-6.

Aggarwal, M., Singh, M., and Gupta, S.K. (2012). 
Integration of Wind Generation system in low voltage distribution system, IEEE 5th India International conference on Power Electronics (IICPE'2012), pp.16.

Aggarwal, M. Singh, M. and Gupta, S.K. (2013). Fault ride through analysis of wind farm in low voltage distribution system, International Journal of Engineering Research and Technology (IJERT).Vol. 2, No. 7, pp. 2212-2219.

Allagui, M., and Hasnauoi, O. (2014). Dynamic performance improvement of wind farm equipped with SCIG generators using STATCOM, Journal of Energy in South Africa, Vol. 25, No. 4, pp.128-135.

Alonso, M., and Amari, H. (2006). Voltage stability in distribution networks with DG, IEEE Power Tech, Bucharest, Romania, pp.1-6.

Anderson, P.M., and Fouad, A.A. (2002). Power System Control and Stability. Wiley, John and Sons, New York, USA.

Banerji, A, Biswas, S.K., and Singh, B. (2012). DSTATCOM control algorithms: a review. International Journal of Power Electronics and Drives Systems (IJPEDS). 2(3), pp. 285-296.

Barker. P.P. and de Mellow. R.W. (2000). 'Determining the impact of distributed on power systems: part1radial distribution systems', Power Engineering Society Summer Meeting, IEEE, Vol.3, pp.11451156.

Coster, E.J., Myrzik, J.M.A., Kruimer, B., and Kling, W.L. (2011). Integration issues of distributed generation in distribution grids, Proceedings of IEEE, pp.28-39.

Ettehadi, M., Ghasemi, H., and Vaez Zadeh, S. (2012). Voltage stability based DG placement in distribution network, IEEE Transaction on Power Delivery, Vol.28, No.1, pp. 171-178.

Freitas, W. Asada, E. Morelato A, and Xu W. (2002). Dynamic improvement of induction generators connected to distribution systems using a DSTATCOM, Proceedings of Power System Technology, Powercon, pp.173-7, 2002.

Freitas, W., Asada, E., Morelato, A., and Xu W. (2011). Study of the impact of wind generation on voltage stability in transmission networks, IEEE Electric utility Deregulation and Restructuring and Power Technologies (DRPT), pp. 39-44.

Ghosh A., and Ledwich G. (2002). Power quality enhancement using custom power devices, Kluwer Academic Publishers, Boston.

Hatziargyriou, N.D. and Melipoulos A.P.S. (2000). Distributed energy sources: Technical challenges, Proceedings of IEEE PES winter meeting, pp. 10171022, Las Vegas, Nevada, USA, 2000.

Hingorani, N.G., and Gyugyi, L. (1999). Understanding FACTS Flexible AC transmission Systems, WileyIEEE Press, New York.

Jeff, W. Smith, D.., and Brooks L. (2001). Voltage impacts of distributed wind generation on rural distribution feeders, IEEE Transmission and Distribution conference and Exposition, pp.492-497.

Kothari, D.P., Singal, K.C., and Ranjan, R. (2012). Renewable Energy Sources and Emerging Technologies, New :Concepts and Technology of Delhi.
Kundur, P. (1994). Power System Stability and Control, Mcgraw Hill, New York, USA.

Lahacani, N.A., Aouzellag, D. and Mendil, B. (2010). Static compensator for maintaining voltage stability of wind farm integration to distribution network, Renewable Energy, Vol. 35, pp.2476-2482.

Palvos, S. Georgilakis (2008). Technical challenges associated with the integration of wind power into power systems, Renewable and Sustainable Energy Reviews, Vol. 12, pp. 852-863.

Roy N.K., Hossain M.J., and Pota HR. (2011). Voltage profile improvement for distributed wind generation using dstatcom. In: IEEE pes general meeting, pp. 16, Detroit, USA.

Roy, N.K., Hossain, M..J., and Pota, H.R. (2013). Reactive power management of distribution networks with wind generation for improving voltage stability. Renewable Energy, Vol. 58, pp.85-94.

Shen, M., Huang, J.M., and Pattani, R. (2012). Steadystate \& dynamic voltage impacts of wind generators on rural distribution systems and practical Distribution Conference and Exposition (T\&D), 2012 IEEE PES, pp.1-8, 2012

Zamora, D. R. Rosado, J.M.A. Diaz Castillo, A.J. (2014). Stability Analysis of Wind generation in electrical system of Puerto Pico, international conference on renewable energy and power quality, Cordoba, Spain.

Received 13 April 2015; revised 24 October 2015 